\title{
Role-semantic parameters for DOM in Italian
}

\begin{abstract}
Italian is said to be a no-DOM language. Some studies have shown, however, that under certain conditions occurrences of DOM-marking can be found in the colloquial spoken variety (Berretta 1989; 1991; Belletti 2018). In a corpus of spontaneous speech of Italian collected by Berretta 1991, DOM seems to appear with verbs associated with "non-prototypical objects", such as ОВJECTEXPERIENCER PSYCH-VERBS (e.g. preoccupare 'worry', spaventare 'frighten') or INTERACTION VERBS (e.g. salutare 'greet', chiamare 'call'). While Berretta's study provides an accurate description of such cases, we investigated possible motivations for the marker to appear. We postulate a hypothesis in terms of role-semantic parameters, based on Dowty's (1991) proto-role model, assuming that the appearance of the $a$-marker is triggered by the proto-agent properties that specific verb types assign to their objects. In order to assess a possible effect of agentivity on DOM in Italian, we carried out an acceptability judgment task in which verb type and NP type of the object have been manipulated. As our results show, verbs with an agentive object are more likely to be accepted with DOM than objects bearing exclusively patient properties. Such hypothesis seems to hold particularly for OBJECT-EXPERIENCER PSYCH-VERBS, where the proto-agent property sentience is entailed for the direct object rather than only presupposed as in the case of INTERACTION VERBS. At the same time, the interaction between verb semantics, referential and syntactic prominence proves to be very relevant, suggesting that DOM in Italian is far from being grammaticalized. Overall, this study is a further contribution supporting the role-semantic model for DOM.
\end{abstract}

\footnotetext{
Acknowledgements: The present paper has been presented as a talk in the Linguistic Colloquium of the University of Cologne and at the Workshop "Differential Object Marking in Spanish (and beyond) - diachronic change and synchronic variation" at the University of Zurich. We thank all participants for their valuable comments and suggestions. Our thanks also go to Javier Caro Reina and Marco García García for support and helpful discussion during the preparation and evaluation of our study. Furthermore, we would like to thank the SFB 1252 "Prominence in language" at the University of Cologne for support, in particular Maximilian Hörl for his help with the statistical analysis of our data, and two anonymous reviewers for their comments on a previous version of this paper.
}

Alessia Cassarà, University of Cologne, e-mail: alessia.cassara@uni-koeln.de Sophie Mürmann, University of Cologne, e-mail: sophie.muermann@uni-koeln.de 
Keywords: agentivity, animacy, colloquial Italian, Differential Object Marking (DOM), judgment tasks, proto-roles, referentiality, role semantics

\section{Introduction}

Italian, as well as French, is usually reported to be a Romance language that does not exhibit the phenomenon of Differential Object Marking (DOM) (cf. e.g. Bossong 1998). Unlike Southern Italian varieties, Standard Italian is said to lack morphological marking of prominent, i.e. animate and definite, direct objects. This view seems to be confirmed if we consider the pair of examples in (1):
(1) a. Questi argomenti non hanno convinto $\varnothing^{*} a$ Gianni. these arguments NEG have.PRS.3PL convinced $\varnothing /$ DOM Gianni 'These arguments haven't convinced Gianni.'

(Belletti 2018, 446)
b. La polizia non ha ferito $\varnothing /{ }^{*} a$ Gianni.
the police NEG have.PRS.3SG injured $\varnothing / \mathrm{DOM}$ Gianni
'The police did not injure Gianni.'

In both (1a) and (1b), $a$-marking of the direct object Gianni would be ungrammatical, independently of the type of verb that accompanies it. In (1a), we deal with the OBJECT-EXPERIENCER (OE) PSYCH-VERB COnvincere 'convince', whereas (1b) shows the highly transitive verb ferire 'injure'. However, once the object moves from its clause-internal position to the left periphery of the sentence, ${ }^{1}$ DOM gets broadly acceptable for speakers of Standard Italian in (2a) but stays ungrammatical in (2b): ${ }^{2}$

\footnotetext{
1 We adopt Belletti's (2018) syntactic analysis of these constructions stating that $a$-marked direct objects in Standard Italian occur in the TopP position within the CP of the sentence. Yet, while Belletti labels these objects $a$-Topics, we refer to them as instances of the more general phenomenon of DOM. It will be stressed below, though, that Belletti's syntactic analysis cannot capture all instances of $a$-marked direct objects in Italian: especially with OE-psych-verbs and causative constructions, $a$-marked objects seem to predominantly occur clause-internally (as in example 6 below).
}

2 Examples (2b), (3b) and (4a-b) are based on the judgment of a native speaker. 
(2) a. $\varnothing /{ }^{\prime} A$ Gianni, questi argomenti non l' hanno $\varnothing /$ DOM Gianni these arguments NEG CL.3SG have.PRS.3PL convinto convinced

'As for Gianni, these arguments have not convinced him.'

b. $\varnothing /{ }^{*} A$ Gianni, la polizia non $l$, ha ferito. $\varnothing /$ DOM Gianni the police NEG CL.3SG have.PRS.3SG injured 'As for Gianni/him, the police did not injure him.'

Even more striking, DOM seems to be rather obligatory than optional with the verb convincere 'convince' if we change the NP type from a personal name to a first- or second-person pronoun (3a). The verb ferire 'injure', on the contrary, is considerably less acceptable with DOM also with a left-dislocated first- or second-person pronoun (3b):

(3) a. ${ }^{*} \varnothing / A \quad m e / t e$, questi argomenti non $\mathrm{m}^{\prime} / \mathrm{t}$ ' hanno $\varnothing /$ Dom 1SG/2sG these arguments NEG CL.1/2sG have.PRS.3PL convinto convinced

'As for me/you, these arguments have not convinced me/you.'

b. $ø / ? A$ me/te, la polizia non $m^{\prime} / t^{\prime}$ ha ferito. $\varnothing /$ DOM $1 \mathrm{SG} / 2 \mathrm{SG}$ the police NEG CL.1/2SG have.PRS.3SG injured 'As for me/you, the police did not injure me/you.'

The reason for the $a$-marker being not completely ruled out in (3b) might be due to the fact that tonic pronouns generally cannot occur in peripheral position in Italian without being $a$-marked. As far as definite human NPs are concerned, we also see a difference of acceptability between the two verbs in question. Whereas DOM is optional with la ragazza 'the girl' with convincere (4a), it is ungrammatical with ferire (4b):

(4) a. $\varnothing / A$ (l) la ragazza, questi argomenti non l' $\varnothing /$ Dom the girl these arguments NEG CL.3SG hanno convinta.

have.PRS.3PL convinced

'As for the girl, these arguments have not convinced her.' 
b. $\varnothing /{ }^{*} A \quad$ (l) la ragazza, la polizia non l' ha $\varnothing /$ DOM the girl the police NEG CL.3SG have.PRS.3SG ferita. injured

'As for the girl, the police did not injure her.'

Restrictions of DOM in Italian which seem to be due to the verb type have been already put forward by Berretta $(1989 ; 1991)$. In a corpus of spontaneous speech, she identifies three groups of verbs or verbal constructions that are attested with DOM in Italian (Berretta 1991, 137-138): ${ }^{3}$

1. OBJECT-EXPERIENCER PSYCH-VERBS: affascinare 'fascinate', attrarre 'attract', colpire 'impress, strike', confortare 'comfort', consolare 'cheer up', convincere 'convince', deludere 'disappoint', disturbare 'disturb', divertire 'entertain', eccitare 'excite', entusiasmare 'excite', incantare 'enchant', ingannare 'deceive', innervosire 'make nervous', invitare 'tempt', mettere (di buon umore) 'cheer', persuadere 'persuade', preoccupare 'worry', rattristare 'sadden', spaventare 'frighten',

2. CAUSATIVE CONSTRUCTIONS: with fare 'make'/lasciare 'let' + infinitive: fare dormire 'make sleep', fare ingrassare 'fatten', fare morir dal ridere 'make die laughing', fare ridere 'make laugh', fare piangere 'make cry', fare sentir male 'make feel bad', lasciare salire 'pick up', lasciare stare 'let be/go', and

3. OTHER VERBS: accompagnare 'accompany', aspettare 'wait for', chiamare 'call', coccolare 'cuddle', conoscere '(get to) know', dannegiare 'damage, harm', fermare 'stop', fregare 'wipe', fucilare 'shoot', graffiare 'scratch', incastrare 'trap', informare 'inform', incolpare 'blame', lasciare (in pace) 'leave sb alone', mandare 'send', mettere (in galera) 'jail', pagare 'pay', picchiare 'beat', portare 'carry', prendere 'take', proteggere 'protect', pungere 'offend', ringraziare 'thank', rovinare 'ruin', salutare 'greet', seppellire 'bury', sposare 'marry', stancare 'tire sb out', stendere 'hang', svegliare 'wake sb up', temere 'fear', toccare 'touch', trattare (male) 'misuse', vedere 'see'

While the first two groups of verbs are precisely classified as (1) OE-PSYCH-VERBS and (2) CAUSATIVE CONSTRUCTIONS, the third group is not further specified, being simply labelled (3) OTHER VERBS. As we will argue in chapter 3.2, a considerable number of verbs of class (3) overlap with a role-semantically defined category called INTERACTION VERBS by Blume (1998). These verbs share the property of not select-

3 All relevant examples of the corpus are listed in the appendix of her article (Berretta 1991, 143-148). 
ing a prototypical patient object but one that bears an equivalent degree of agentivity as the subject.

Importantly, as we have seen in the examples (1)-(4) above, DOM with the listed verbs and verbal constructions faces further semantic and syntactic constraints: its degree of acceptability depends on (i) whether the direct object is expressed by a strong personal pronoun, a personal name or a human definite $\mathrm{NP}$, and it is restricted to (ii) direct objects appearing in (left- $)^{4}$ peripheral sentence position but not in canonical SVO word order. Both points require further specifications. As for (i), it has to be added that also indefinite generic NPs can bear DOM. These instances of DOM in Italian have not received attention in the literature so far. An example from Berretta's corpus is given in (5):
(5) Ad un linguista possono colpire particolarmente [...] DOM a linguist can.PRS.3PL impress particularly frasi del seguente tenore phrases of the following tenor 'A linguist may be particularly impressed by [...] phrases of the following tenor.'

(Berretta 1991, 143f.)

Note that the verb colpire is used in its OE-PSYCH reading 'impress, strike' here. In contrast to the previous examples, it is questionable if we deal with an instance of left-dislocation in (5) or rather with a clause-internal object in OVS word order. Since the sentence lacks a resumptive clitic, we would argue in favour of the latter analysis. This leads us to the syntactic constraint in (ii), which needs to be refined. Contrary to the syntactic analysis given by Belletti (2018), Berretta's corpus data reveal that for a majority of cases $a$-marked objects of OE-PSYCH-VERBS and CAUSATIVE CONSTRUCTIONS are not dislocated but rather clause-internal direct objects:

(6) a. OE-PSYCH-VERB
A me non convince.
DOM 1SG NEG convince.PRS.3SG
'I am not convinced.'

\footnotetext{
4 In Berretta's corpus, marked objects appear in the left periphery (or sentence-initially) in $80.4 \%(74 / 92)$ of the cases in contrast to $19.6 \%$ (18/92) in the right periphery.
} 
b. CAUSATIVE CONSTRUCTION

A me fanno piangere.

DOM 1SG make.PRS.3PL cry

'They make me cry.'

(Berretta 1991, 139)

The lack of a resumptive clitic in (6a) and (6b) is a strong indicator that we deal with a pre-posed direct object in these cases. As remarked by Berretta $(1991,139)$, $a$-marked objects like in (6) also differ in register from their clitic-left-dislocated counterparts (cf. $7 \mathrm{a}$ and $7 \mathrm{~b}$ ). While the former can be characterized as sociolinguistically unmarked, appearing also in more formal registers, the latter are clearly confined to colloquial registers.

(7) a. OE-PSYCH-VERB

A me non mi convince.

DOM 1SG NEG CL.1SG convince.PRS.3SG

'As for me, I am not convinced.'

b. CAUSATIVE CONSTRUCTION

A me mi fanno piangere.

DOM 1SG CL.1SG make.PRS.3PL cry

'As for me, they make me cry.'

(Berretta 1991, 139)

A similar point had been made by Benincà $(1986,232)$, though for OE-PSYCH-VERBS only. She states that DOM with OE-PSYCH-VERBS also appears in the written language where even the lack of $a$-marking is perceived as ungrammatical. With other verbs, such as invitare 'invite' in contrast, DOM is limited to colloquial contexts. In these cases, the object is always dislocated as in (8a), a variant with the object occurring sentence-initially like in (8b) would not be of a higher register but simply pragmatically odd (cf. Berretta 1991, 139).

(8) a. A me non mi hanno invitato. DOM 1SG NEG CL.1SG have.PRS.3PL invited 'As for me, they did not invite me.'

(Benincà 1986, 232)

b. \#A me non hanno invitato. DOM 1SG NEG have.PRS.3PL invited 'They did not invite me.' 
The particular status of OE-PSYCH-VERBS and CAUSATIVE CONSTRUCTIONS is borne out by the distribution of the resumptive clitic among the three verbs classes differentiated by Berretta: while OE-PSYCH-VERBS (75\%, 30/40 occurrences) and CAUSATIVE CONSTRUCTIONS $(62.5 \%, 5 / 8)$ are for the most part attested without a resumptive clitic, ${ }^{5}$ the third class of OTHER VERBS overwhelmingly occurs with a clitic (present in $86.4 \%$ of the occurrences, 38/44, cf. Berretta 1991, 139). Another closely related tendency is that the former two classes strongly prefer the left position, while the latter also occur in contexts with right-dislocated marked objects. In these cases, the resumptive clitic is nearly always present, as in non t'ho visto a te 'I have not seen, DOM you' (cf. Berretta 1991, 128-132). For our purposes, both subtypes of the syntactic constraint (ii) can be reconciled: what both pre-posed and dislocated $a$-marked objects have in common is a deviation from canonical SVO word order with the direct object occurring in a non-prototypical syntactic position. Since only $a$-marked dislocated direct objects occur across verb classes, most typically as Clitic Left Dislocations (CLLDs), we will focus on this phenomenon which is arguably confined to colloquial registers of Italian. The aim of the present paper is thus to obtain a more detailed picture on the acceptability of $a$-marked direct objects in CLLDs by testing the structure with predicate classes showing different role-semantic configurations as well as with different NP types of the object.

Besides Berretta (1989; 1991), several other authors have discussed the occurrences of DOM in colloquial Standard Italian (cf. Benincà 1986; Iemmolo 2010; in preparation; Belletti 2018). Whereas these approaches mainly seek explanations for the phenomenon in terms of information structure and argue in favour of a topic-marking function of DOM in Italian, the present article wants to elaborate on the role-semantic properties that characterize $a$-marked objects. This is of interest for mainly two reasons: first, research on DOM in Spanish has revealed that the consideration of role-semantic factors is fruitful for the investigation of DOM in general offering a more adequate explanation for the phenomenon than purely nominal-based or information-structural approaches (cf. Weissenrieder 1991; García García 2007; 2014; Primus 2012; Kabatek 2016; García García/Primus/

5 Certainly, a further analysis would be required in order to separate the cases in which the clause-internal clitic is indeed absent from those in which it is not overtly expressed but present in the structure. As for the latter cases, it must be considered that the lack of an overt clitic might also be attributed to a matter of register since prescriptive grammars of Italian ban cliticdoubling. Thus, overtly expressed clitics are expected to be used in less formal registers whereas they are more likely to be absent in formal settings. However, reconsidering that Berretta's corpus consists of data of spontaneous speech recorded in informal settings, it does not seem satisfactory to reduce the lack of the clitic to a question of register. 
Himmelmann 2018). Second, the fact that DOM in Italian, in contrast to Spanish, has not been grammaticalized yet, allows for a fine-grained analysis of semantic, pragmatic and syntactic constraints that have to interact systematically for the marker to occur. These initial triggering factors are difficult to disentangle in Modern Spanish, since the $a$-marking of nearly every human definite direct object blurs the underlying concepts, such as individuation or agentivity.

The paper is structured as follows: Section 2 introduces the theoretical framework of generalized semantic roles employed, exemplified for Spanish DOM. Section 3 offers a role-semantic analysis of two DOM-sensitive verb classes in Italian, namely OE-PSYCH-VERBS and INTERACTION VERBS. Likewise, we will sketch additional constraints on DOM which concern NP type and syntactic position. Section 4 presents our online acceptability judgment task through which we tested the effect of role semantics in interaction with NP type for left-dislocated objects in colloquial Standard Italian. Section 5 draws the conclusions arguing that among the factors favouring DOM in Italian, agentivity should be treated on par with referential prominence and topicality.

\section{DOM and generalized semantic roles}

In order to examine the influence of role-semantic factors for Italian DOM, we shall motivate a role-semantic approach on DOM in general in a first step. This can be illustrated by Spanish which is usually said to have an animacy- and definiteness-based DOM system (cf. e.g. Aissen 2003). Such interpretation is confirmed by (9) and (10):

(9) Conozco $\varnothing /{ }^{*} a$ esta película. know.PRS.1SG $\varnothing /$ DOM this film 'I know this film.'

(10) Conozco ${ }^{*} ø / a$ este actor. know.PRs.1SG $\varnothing /$ DOM this actor 'I know this actor.'

(García García 2007, 63)

Whereas $a$-marking of the inanimate, though definite object NP esta película 'this film' in (9) would be ungrammatical, the marker must occur obligatorily with the human definite NP este actor 'this actor' in (10). However, the following examples 
challenge a purely animacy- and definiteness-based approach on DOM and, as we will further argue, support a role-semantic analysis.

(11)

Un artículo precede
a article precede.PRS.3SG $\varnothing /$ /DOM a an noun
'An article precedes a noun.'

(12) La euforia caracteriza ${ }^{*} \varnothing / a \quad$ la situación. the euphoria characterize.PRS.3SG $\varnothing / \mathrm{DOM}$ the situation 'Euphoria characterizes the situation.'

(García García 2018, 226)

As examples (11) and (12) illustrate, animacy is not a necessary criterion for DOM to appear in Spanish. In both examples, we find an inanimate object which in (11) must be obligatorily $a$-marked to obtain a grammatical sentence and in (12) is highly preferred with the marker. Instead, the occurrence of DOM in both examples could be explained by role-semantic factors: considering the semantic roles of both subject and object, we see that in (11) and (12) the prototypical AGENTPATIENT-asymmetry of a transitive sentence is not respected. García García (2007; 2014; 2018) captures this in his generalization of THEMATIC DISTINCTNESS:

(13) Generalization of thematic distinctness:

DOM in Spanish is required with inanimate objects when the subject does not outrank the direct object in terms of agentivity.

(García García 2007, 71; 2014, 145; 2018, 227)

The approach of García García is based on Dowty’s (1991) proto-role model. This model has originally been established to account for lexicalization patterns of predicates, exemplified with English transitive verbs. Later research mainly used Dowty's model in order to make predictions on argument realization phenomena, i.e. to explain the mapping from lexical semantics to syntax as well as morphosyntactic linking. We will shortly introduce the main ideas of the model before motivating its applicability to differential morphosyntactic argument realization. Dowty elaborates the concept of two generalized semantic roles, one proto-agent and one proto-patient. Each of these two cluster roles consists of five different properties listed below:

(14) AGENT PROTO-ROLE:

a. volitional involvement in the event or state

b. sentience (and/or perception) 
c. causing an event or change of state in another participant

d. movement (relative to the position of another participant)

(e. exists independently of the event named by the verb)

(Dowty 1991, 572)

(15) PATIENT PROTO-ROLE:

a. undergoes change of state

b. incremental theme

c. causally affected by another participant

d. stationary relative to movement of another participant

(e. does not exist independently of the event, or not at all)

(Dowty 1991, 572)

Based on these proto-properties, which are understood as verbal entailments in the strictly logical sense, Dowty formulates an argument selection principle and two corollaries that predict how subject and direct object selection can be deduced from the accumulation of proto-agent and proto-patient properties of a predicate. It is predicted that the argument bearing a higher number of proto-agent properties is lexicalized as the subject and the argument having a higher number of proto-patient properties is lexicalized as the direct object (cf. Dowty 1991, 576). Thus, the model correctly predicts that in a sentence like Peter ate an apple or Peter wrote a letter, Peter bearing all the given protoagent properties is realized as the subject and an apple/a letter having all the indicated proto-patient properties is realized as the direct object, respectively. One great advantage of the model, which is essential for the present approach, is the possible assignment of proto-agent properties to both arguments as well as the possible combination of proto-agent and proto-patient properties for each argument. While Dowty's model is restricted to English and does not provide corollaries for morphosyntactic argument realization, it has been successfully adopted and refined in later work to make generalizations about universal preferences in morphosyntactic case selection (cf. Blume 1998; 2000; Primus 1999a; 1999b; 2006; Ackerman/Moore 2001).

Coming back to the systematic cases of $a$-marked inanimate objects in Spanish, we can now elaborate on García García’s (2007, 71; 2014, 145; 2018, 227) relational understanding of agentivity, as stated in the generalization in (13), more precisely. Taking into account the distribution of proto-role entailments of a transitive predicate, two scenarios could lead to a lack of thematic distinctness, that is either 
(i) when both subject and object bear the same number of proto-agent properties (e.g. REVERSIBLE-CONVERSE PREDICATES, such as preceder 'precede', seguir 'follow' or REVERSIBLE-SYMMETRICAL PREDICATES, such as igualar 'equal') ${ }^{6}$ or

(ii) when the object has more proto-agent properties than the subject (e.g. VERBS OF ATTRIBUTION, such as caracterizar 'characterize' or definir 'define')

The configuration in (i) is reflected in examples such as Los dias siguen ${ }^{\star} \varnothing / a$ las noches 'The days follow the nights' (or in 11 above) where we find a REVERSIBLE PREDICATE with two participants bearing each the proto-agent property of independent existence. This needs further specification: as Dowty (1991, 572) himself mentions, the status of independent existence as a proto-role entailment is unclear since the term covers various dimensions. On the one hand, it expresses a de re (vs. de dicto) reading of the noun phrase in question, given e.g. for the subject but not for the object in John needs a new car. Note that this dimension concerns rather the semantic domain of specificity than the semantics of the verb. On the other hand, the criterion expresses that a referent "is not brought into being or destroyed by the event named by the verb but is presumed to exist before and after the event" (Dowty 1991, 573). Independent existence is implied by all other proto-agent properties $(9 a-d)$. That it can be interpreted as a core criterion for the causal relation between the arguments has been shown by Primus' (1999a; 1999b; 2006) modified version of Dowty's proto-role model. Here, we can only outline her innovation in a simplified way: in her model, Primus defines the proto-patient role by its dependency from the proto-agent role. This co-argument dependency relation is based on a very broad understanding of causality. The degree of involvement of the proto-patient is thus dependent from the involvement of the proto-agent, characterized by a set of proto-properties which is comparable to the ones presented above in (14) and (15). ${ }^{7}$ Dealing with REVERSIBLE PREDICATES, such as the ones mentioned in (i), none of the proto-agent (14a-d) and proto-patient properties $(15 \mathrm{a}-\mathrm{d})$ are assigned to the arguments, so that there is no involvement dimension between them. That means that a co-argument dependency relation between subject and direct object cannot be established.What follows from

6 While for REVERSIBLE-SYMMETRICAL PREDICATES, subject and object are interchangeable without imposing a change in truth-conditions, in case of REVERSIBLE-CONVERSE PREDICATES, the predication can be reversed through a lexical doublet (cf. García García 2014, 147-170).

7 The main modification in comparison to Dowty's $(1991,572)$ set of entailments is that Primus' proto-properties are defined as primitive predicates and that for each proto-agent predicate a converse proto-patient predicate can be derived. Her list of primitive predicates includes the following notions: CONTROLLER vs. CONTROLLED, CAUSER VS. CAUSALLY AFFECTED, MOVER VS. MOVED, EXPERIENCER VS. EXPERIENCED, and POSSESSOR Vs. POSSESSED (cf. Primus 1999b, 141; 2012, 73). 
that, is that both arguments qualify as weak proto-agents (cf. Primus 2006, 56-59; García García 2014, 144-149). So, in the configuration in (i), subject and direct object are both (weak) proto-agents and are thus not distinguishable in terms of their semantic roles.

The configuration in (ii) involves an even more dramatic deviation from the thematic distinctness we would expect in a prototypical transitive sentence: in sentences such as La seriedad caracteriza ${ }^{\star} \varnothing / a$ su atuendo 'Seriousness characterizes his outfit' (or in 12 above), the subject merely denotes a property of the object and does not have argument status (cf. García García 2014, 171-172), whereas the object can be qualified as agentive since it bears the proto-agent property of independent existence. ${ }^{8}$ The role-semantic explanation to DOM with inanimate objects has also been proven promising for DOM with animate objects (Primus 2012). Whereas the former case shows an actual need for disambiguation of subject and direct object, it has been argued that in the case of animate objects it is rather their potential agentivity in the given event that could blur the distinctness of the two arguments.

To sum up, we have seen how a model of generalized semantic roles can be used to account for examples of DOM in Spanish with inanimate objects which at first sight contradict traditional - animacy-based - approaches. Putting it more precisely, DOM in these cases seems to be triggered by a lack of thematic distinctness between subject and direct object. In order to see whether a similar hypothesis can be developed for the instances of DOM in colloquial Standard Italian, we will continue by a role-semantic analysis of two relevant verb classes as a next step.

\footnotetext{
8 As has been pointed out by a reviewer, the configuration in (ii) does imply distinctness of subject and direct object. While this holds true, the crucial point is that we deal with a sharp deviation from the canonical distinctness of arguments in a transitive sentence, where the subject outranks the object in terms of agentivity. In the case of VERBS OF ATTRIBUTION, the deviation from the prototypical AGENT-PATIENT-asymmetry is even more remarkable since the subjects do not even have argument status. Normally, in such case, linking theories would predict the agentive object to be realized as the subject. As argued by García García (2014, 176-177), the opposite linking pattern in Spanish can be accounted for by lexical economy: ATTRIBUTION VERBS like caracterizar 'characterize' also have another - more frequent - reading in which the subject outranks the direct object in terms of agentivity (e.g. Ana ha caracterizado la situación 'Ana characterized the situation', cf. García García 2014, 177). Hence, for reasons of economy, the valency frame is not changed in the attributive - less usual - reading and the non-prototypicality of the object is indicated by DOM instead.
} 


\section{A role-semantic account on DOM in Italian}

The present Section puts forward the argument that two verb classes that are attested with DOM in Italian, namely OE-PSYCH-VERBS (3.1) and INTERACTION VERBS (3.2), ${ }^{9}$ can be grasped within a role-semantic account using the framework introduced in the previous Section. Our theoretical part is completed by a sketch of two additional constraints for DOM in Italian, i.e. NP type and syntactic position of the object, in Section 3.3.

The following examples (16) and (17) illustrate the requirement of the $a$-marker with OE-PSYCH-VERBS and INTERACTION VERBS if the object is a tonic pronoun and situated in the left periphery of the sentence. Note that although the label INTERACTION VERB has not been employed by Berretta (1991), we will prove its adequacy in Section 3.2 by role-semantic criteria that allow for a systematic classification of a number of verbs of her group of OTHER VERBS under this notion.

OE-PSYCH-VERB

${ }^{*} \varnothing / A$ me preoccupa Torino: è una città difficile.

DOM 1SG worry.PRS.3Sg Torino be.PRS.3SG a city difficult

'Torino worries me: it is a difficult city.'

(Berretta 1991, 147)

(17) INTERACTION VERB

${ }^{*} \varnothing /$ A loro le aspettava Adone in doppiopetto blu.

DOM 3PL CL.3PL wait.for.PST.3SG Adone in double-breasted blue

'Adone waited for them in a blue double-breasted (suit).'

(Berretta 1991, 143)

In both (16) and (17), the omission of DOM would turn the sentence ungrammatical. For HIGHLY TRANSITIVE VERBS such as ferire 'injure', in contrast, the acceptability of the marker considerably decreases:

(18) HIGHLY TRANSITIVE VERB

$\varnothing^{*} A$ me mi ha ferito la polizia due anni

DOM 1SG CL.1SG have.PRS.3SG injured the police two years

fa

fare.PRS.3SG

'The police injured me two years ago.'

9 CAusative Constructions which, as identified by Berretta (1991), also show a high preference for DOM in Italian are not considered in the present work. 
In what follows, we will elaborate on the role-semantic properties of the two DOM-sensitive verb classes of OE-PSYCH-VERBS and INTERACTION VERBS and point out what distinguishes them from HIGHLY TRANSITIVE VERBS.

\subsection{OE-PSYCH-VERBS}

Transitive OE-PSYCH-VERBS are a construction type of psychological predicates in which the STIMULUS is encoded as the subject and the EXPERIENCER as the direct object (e.g. annoy, frighten, impress). They can be contrasted with transitive SUBJECT- EXPERIENCER (SE)-PSYCH-VERBS which exhibit the reverse linking pattern taking an EXPERIENCER subject and a STIMULUS object (e.g. adore, love, hate) (cf. e.g. Verhoeven 2014, 130). As argued by Kutscher (2009, 27-40) and many others (e.g. Croft 1993; cf. Kailuweit 2005; 2015 for Romance languages), against Dowty (1991, 580), OE-PSYCH-VERBS are an aspectually heterogeneous class. Furthermore, they vary in their causal structure. A distinction is usually made between causative (or agentive) and non-causative (or non-agentive) OE-PSYCH-VERBS. It is language-specific if non-causative PSYCH-VERBS form a separate lexical class or if a language only has one lexical class of \pm causative PSYCH-VERBS (cf. Verhoeven 2014, 131-132). Italian, as well as the other Romance languages, has both classes as illustrated in (19) vs. (20):

(19) a. NON-CAUSATIVE

Maria ha affascinato Pietro (*con intenzione).

Maria have.PRS.3Sg fascinated Pietro (intentionally)

'Maria fascinated Pietro (*intentionally).'

b. Le domande di Maria hanno affascinato Pietro

The questions of Maria have.PRS.3PL fascinated Pietro

( ${ }^{*}$ con intenzione).

(intentionally)

'Maria’s questions fascinated Pietro (`intentionally).'

(20) a. \pm CAUSATIVE

Maria ha disturbato Pietro (con intenzione).

Maria have.PRS.3sg disturbed Pietro (intentionally)

'Maria disturbed Pietro (intentionally).' 
b. Le domande di Maria hanno disturbato Pietro

The questions of Maria have.PRs.3PL disturbed Pietro ( ${ }^{*}$ con intenzione). (intentionally) 'Maria’s questions disturbed Pietro (`intentionally).'

The non-causative PSYCH-VERB affascinare 'fascinate' cannot obtain an agentive, i.e. volitional reading, regardless of whether the subject is animate (19a) or inanimate (19b). The causative PSYCH-VERB disturbare 'disturb', conversely, can be interpreted as agentive with an animate subject (20a) but stays non-agentive with an inanimate subject (20b). Hence, the causative reading can only arise with an animate (or better human) subject which is typically interpreted to act volitionally in the event.

Table 1 shows how OE-PSYCH-VERBS can be analyzed in terms of Dowty's proto-role entailments.

Table 1: Distribution of proto-properties for OE-PSYCH-VERBS.

\begin{tabular}{|c|c|c|c|}
\hline \multirow[t]{2}{*}{ Verb class } & \multirow{2}{*}{$\begin{array}{l}\text { Subject } \\
\text { P-agent }\end{array}$} & \multicolumn{2}{|c|}{ Direct Object } \\
\hline & & P-agent & P-patient \\
\hline \multicolumn{4}{|l|}{ OE-PSYCH } \\
\hline (A) NON-CAUSATIVE & + independent ex. & & \\
\hline $\begin{array}{l}\text { (e.g. affascinare 'fascinate', } \\
\text { deludere 'disappoint', } \\
\text { incantare 'enchant') }\end{array}$ & & $\begin{array}{l}\text { + sentience } \\
\text { + independent ex. }\end{array}$ & \pm change of state \\
\hline (B) \pm CAUSATIVE & \pm volition & & \\
\hline (e.g. disturbare 'disturb', & \pm sentience & + sentience & + causally affected \\
\hline $\begin{array}{l}\text { divertire 'entertain', } \\
\text { spaventare 'frighten') }\end{array}$ & $\begin{array}{l} \pm \text { causation } \\
+ \text { independent ex. }\end{array}$ & + independent ex. & \pm change of state \\
\hline
\end{tabular}

As for non-causative OE-PSYCH-VERBS and \pm CAUSATIVE VERBS in their noncausative reading, the subject is solely assigned the proto-agent property independent existence, while the direct object bears sentience and independent existence. In addition, the object can undergo a change of state and hence also exhibit a proto-patient property. In their causative reading, the subject bears the protoagent properties of causation and independent existence. Likewise, the object has two proto-agent properties, namely sentience and independent existence. As a proto-patient property, the object entails causally affected and, optionally, also change of state. Moreover, as seen above, human subjects can be interpreted as volitionally acting participants (and since volition implies sentience, also 
as sentient participants). ${ }^{10}$ So, while for non-causative PSYCH-VERBS the object outranks the subject in terms of agentivity, in case of causative PSYCH-VERBS the subject is more agentive than the object. However, there is one criterion which distinguishes causative OE-PSYCH-VERBS from prototypical TRANSITIVE VERBS, namely the object bearing the proto-agent property of sentience. Sentience is defined by Dowty $(1991,573)$ in the following way: "Sentience means more than a presupposition that an argument is a sentient being; it is rather sentience with respect to the event or state denoted by the verb". This proto-agent property overlaps with one or two proto-patient properties for the object. Hence, one could argue that due to this role overlap, also for causative OE-PSYCH-VERBS a clear-cut co-argument dependency is blurred (cf. Primus 2012, 73).

In (21) and (22), we list again the OE-PSYCH-VERBS attested with DOM by Berretta (1991, 137f.), now divided into NON-CAUSATIVE and \pm CAUSATIVE VERBS:

(21) NON-CAUSATIVE: affascinare 'fascinate', attrarre 'attract', colpire 'strike', confortare 'comfort', consolare 'cheer up', convincere 'convince', deludere 'disappoint', entusiasmare 'excite', incantare 'enchant', ingannare 'deceive', persuadere 'persuade', preoccupare 'worry'

(22) \pm CAUSATIVE: disturbare 'disturb', divertire 'entertain', eccitare 'excite', innervosire 'make nervous', invitare 'tempt', mettere (di buon umore) 'cheer', rattristare 'sadden', spaventare 'frighten'

Benincà (1986, 239, fn. 14) makes an interesting remark with regard to the abovemade distinction suggesting that the reading of an OE-PSYCH-VERB (causative or non-causative) affects the acceptability of DOM in Italian. She takes the ambiguous sentence Giorgio non mi ha convinto 'Giorgio did not convince me', which can have the following two interpretations depending on the subject's agentivity:

(i) Il comportamento di Giorgio non è risultato per me convincente.

'Giorgio's behaviour was not convincing to me.' [- CAUSATIVE]

(ii) Giorgio non è riuscito a convincermi (a prestargli un milione).

'Giorgio couldn't convince me (to lend him a million).' [+ CAUSATIVE]

If in such context, the sentence $A$ me, Giorgio non mi ha convinto 'DOM me, Giorgio did not convince me' was uttered, it would be generally accepted and unmarked with respect to register with the reading in (i), while it would be con-

10 Strictly speaking, volition and sentience are conveyed in these cases via conversational implicature rather than via lexical entailment (cf. Primus 1999a, 51). 
fined to colloquial registers with the reading in (ii). If this holds true, it might indicate that the degree of thematic distinctness between subject and object has an impact on the general acceptability of DOM in Italian. Note, however, that the assumption that the $a$-marked CLLD structure above can be interpreted as either sociolinguistically unmarked or marked is somewhat contradictory to the claim of Berretta (1991, 139), who ascribes a general colloquial flavour to structures with $a$-marked in CLLDs.

It must be noted that Italian has another construction type of non-causative PSYCH-VERBS which must be clearly differentiated from the OE-PSYCH-VERBS in question. This type is most prototypically represented by VERBS OF LIKING (cf. Kailuweit 2005), such as piacere 'like' which select for an indirect object (e.g. A Gianni piace la pittura 'Gianni likes the painting'). The presented examples of $a$-marked objects with OE-PSYCH-VERBS can be disproved to be indirect objects for the following two reasons: first, if the dislocated object is coindexed by a clitic, we always find the direct object clitic (though only visible for the $3^{\text {rd }}$ person: A lui lo preoccupa 'It worries him' vs. colloquial $A$ lui gli piace 'He likes it'). Second, and even more convincing, we cannot have an $a$-marked object of oE-PSYCHVERBS in canonical word order: ??ø/A lui lo preoccupa la situazione 'The situation worries him' vs. La situazione preoccupa * a lui (correct only: La situazione lo preoccupa). ${ }^{11}$ When we deal with an indirect object, in contrast, the insertion of $a$ in the canonical sentence is possible: A lui non (gli) piace Gianni 'He does not like Gianni' vs. Gianni non piace a lui/Gianni non gli piace. So, we deal indeed with two different structures here and cannot treat the cases of DOM as instances of indirect objects.

\subsection{INTERACTION VERBS}

As will be argued in the following, there is a second semantically defined verb class that shows a preference for DOM in Italian. This class is labelled INTERACTION VERBS by Blume $(1998,254)$ and comprises (typically) two-place predicates which denote complex events of social interaction. Representative examples are verbs such as 'help', 'greet' or 'thank'.

11 There are instances, though, in which tonic pronouns can appear in canonical object position with transitive verbs, namely when they appear in emphatic contexts (e.g. accompanied by focus particles such as solamente 'only' or anche 'too'), as in La situazione preoccupa solamente $\left({ }^{*}\right.$ a $)$ lui ‘The situation only worries him' (cf. also Benincà 1986, 231). As expected, DOM would be ungrammatical in these cases. We thank a reviewer for this remark. 
In terms of role semantics, the only property that holds for members of this class is the proto-agent property of independent existence which is entailed both for the subject and the direct object. The implication of volition (and sentience) for the subject varies from verb to verb. It is given e.g. for the subject of chiamare 'call' and salutare 'greet' but only pragmatically inferred by conversational implicature for aiutare 'help' which can therefore also be referred to as being "semantically underspecified for volition” (Primus 2012, 85). What is important here is that the object does not bear any proto-patient property. There is thus no co-argument dependency relation between the two arguments, which both bear at least one proto-agent property.

Table 2: Distribution of proto-properties for INTERACTION VERBS.

\begin{tabular}{llll}
\hline Verb class & $\begin{array}{l}\text { Subject } \\
\text { P-agent }\end{array}$ & \multicolumn{1}{c}{ Direct Object } \\
\cline { 3 - 3 } & & P-agent & P-patient \\
\hline INTERACTION & \pm volition & {$[ \pm \text { volition }]_{\text {PRESUPPOSED }}$} \\
(e.g. aspettare 'wait for', & \pm sentience & {$[ \pm \text { sentience }]_{\text {PRESUPPOSED }}$} \\
chiamare 'call', salutare 'greet') & \pm movement & {$[ \pm \text { movement }]_{\text {PRESUPPOSED }}$} \\
& + independent ex. & + independent ex. \\
\hline
\end{tabular}

We say at least one proto-agent property since, in addition to the entailed property independent existence, the object of a social interaction event also bears one or more presupposed proto-agent properties (cf. Table 2). Our point of departure for introducing presupposed proto-agent properties is Blume's (1998) modified version of Dowty's (1991) proto-role model, which she uses in order to account for the morphosyntactic linking of INTERACTION VERBS cross-linguistically. In her model, proto roles are understood as relations of participants to subevents. She assumes the object of verbs like 'thank', 'answer' and 'call' to bear proto-agent properties in a presupposed subevent. This subevent is temporally prior to the entailed subevent in which the subject participant is acting. To be more precise, we seem to deal with a very general presupposition of sentience for the object argument, which is of the following kind: "y is a sentient being, able to perceive (and react) in the given event" or, even more simple, “y is autonomously active”. As a proper presupposition, and unlike a predicate entailment, it is kept constant under negation: Thus, it would be also true for the object of a sentence like Peter did not greet Maria which carries the presupposition that Maria would have been able to perceive Peter's greeting and react to it. There are some pieces of evidence that presupposed sentience of the object, probably together with the lack of an AGENT-PATIENT-asymmetry, has an impact on morphosyntactic argument reali- 
zation. First, as revealed by Blume (1998; 2000), INTERACTION VERBS display the cross-linguistic tendency to select marked case frames, e.g. NOMINATIVE/DATIVE. Second, there are examples like (23) in Spanish where DOM occurs with an inanimate object that can be ascribed presupposed sentience in the event denoted by the predicate:
¡Hans, puñeta, llam-a
al
ascensor!
Hans, damn, call.PRS.3SG Dom.the elevator
'Hans, damn, call the elevator!'

(García García 2014, 189; García García/Primus/Himmelmann 2018, 30)

In this case, the insertion of an inanimate $a$-marked object can be explained as follows: since an elevator is programmed to perceive a certain signal and to react to it, it can be qualified as sentient, and hence agentive, in the given context (cf. García García/Primus/Himmelmann 2018, 32). But, unlike for human beings, the sentience of elevators is restricted to the programmed stimulus, that is why they cannot context-independently fill the slots of other predicates entailing or presupposing sentience (e.g. 'love', 'cuddle', 'be jealous'), while humans can. Hence, the example in (23) nicely illustrates the relative dimension of presupposed proto-agent properties and its possible impact on DOM, at least for Spanish.

Among Berretta's $(1991,138)$ third group of OTHER VERBS, we can identify a dozen of verbs which match the role-semantic criteria shown above and that can thus be subsumed under the class of INTERACTION VERBS: ${ }^{12}$

INTERACTION VERBS:

accompagnare 'accompany', aspettare 'wait for', chiamare 'call', coccolare 'cuddle', informare 'inform', lasciare (in pace) 'leave sb alone', mandare 'send', ringraziare 'thank', salutare 'greet', sposare 'marry'13

12 Certainly, in the mixed group that Berretta provides, there are also verbs which entail proto-patient properties for the object (e.g. graffiare 'scratch', incolpare 'blame', mettere (in galera) 'jail'). However, we made sure that the ones used to build our claim and in the judgment task (Section 4) assigned a balanced degree of agentive properties to subject and object. A further analysis must show if the remaining verbs share similarities. Interestingly, a number of them prototypically select a human (or at least animate) direct object or denotes an event of physical contact.

13 With difference to all other INTERACTION VERBS listed, the verb sposare 'marry' does not presuppose but entails the proto-agent properties volition and sentience to its object argument. 
Table 3 compares the two classes of OE-PSYCH-VERBS and INTERACTION VERBS to HIGHLY TRANSITIVE VERBS, such as uccidere 'kill', ferire 'injure' and arrestare 'arrest'. The latter verbs show a prototypical AGENT-PATIENT-asymmetry with the subject bearing at least the proto-agent properties of causation, movement and independent existence and the object having the proto-patient properties causally affected, stationary participant and change of state. So, in comparison to the objects of the previously mentioned verb classes, HIGHLY TRANSITIVE VERBS show a clearcut distinction of subject and direct object in terms of their semantic roles.

Table 3: Distribution of proto-properties for OE-PSYCH-VERBS, INTERACTION VERBS and HIGHLY TRANSITIVE VERBS.

\begin{tabular}{|c|c|c|c|}
\hline \multirow[t]{2}{*}{ Verb class } & \multirow{2}{*}{$\begin{array}{l}\text { Subject } \\
\text { P-agent }\end{array}$} & \multicolumn{2}{|c|}{ Direct Object } \\
\hline & & P-agent & P-patient \\
\hline $\begin{array}{l}\text { OE-PSYCH } \\
\text { (A) NON-CAUSATIVE } \\
\text { (e.g. affascinare 'fascinate', } \\
\text { deludere 'disappoint', } \\
\text { incantare } \\
\text { 'enchant') }\end{array}$ & + independent ex. & $\begin{array}{l}\text { + sentience } \\
\text { + independent ex. }\end{array}$ & \pm change of state \\
\hline $\begin{array}{l}\text { (В) } \pm \text { CAUSATIVE } \\
\text { (e.g. disturbare 'disturb', } \\
\text { divertire 'entertain', } \\
\text { spaventare 'frighten') }\end{array}$ & $\begin{array}{l} \pm \text { volition } \\
\pm \text { sentience } \\
\pm \text { causation } \\
+ \text { independent ex. }\end{array}$ & $\begin{array}{l}\text { + sentience } \\
\text { + independent ex. }\end{array}$ & $\begin{array}{l}\text { + causally affected } \\
\pm \text { change of state }\end{array}$ \\
\hline INTERACTION & $\begin{array}{l} \pm \text { volition } \\
\pm \text { sentience } \\
\pm \text { movement } \\
+ \text { independent ex. }\end{array}$ & $\begin{array}{l}{[ \pm \text { volition }]_{\text {PRESUPPOSED }}} \\
{[ \pm \text { sentience }]_{\text {PRESUPPOSED }}} \\
{[ \pm \text { movement }]_{\text {PRESUPPOSED }}} \\
+ \text { independent ex. }\end{array}$ & \\
\hline HIGHLY TRANSITIVE & $\begin{array}{l} \pm \text { volition } \\
\pm \text { sentience } \\
\text { + causation } \\
+ \text { movement } \\
\text { + independent ex. }\end{array}$ & & $\begin{array}{l}\text { + change of state } \\
\pm \text { incremental theme } \\
+ \text { causally affected } \\
+ \text { stationary part. } \\
\pm \text { dependent ex. }\end{array}$ \\
\hline
\end{tabular}

To summarize, the role-semantic analysis of OE-PSYCH-VERBS and INTERACTION VERBS has revealed that both classes deviate from the prototypical AGENT-PATIENTasymmetry of a transitive sentence. We would thus suggest that the affinity of these classes to take DOM in Italian can be accounted for by their lack of thematic distinctness. However, only the class of non-causative OE-PSYCH-VERBS satisfies the generalization of thematic distinctness established for Spanish in (13) above 
in the strict sense: for this class, the object outranks the subject in terms of agentivity. For \pm causative OE-PSYCH-VERBS, in contrast, an AGENT-PATIENT-asymmetry can be established in their causative reading. Yet, thematic distinctness may be blurred since proto-patient and proto-agent properties overlap for the direct object. The class of INTERACTION VERBS does not suffice the generalization of thematic distinctness in a strict sense either since the subject might outrank the object in number of proto-agent properties. Crucially, though, no co-argument dependency relation between subject and object can be established since both participants are independently agentive in two different subevents of which one is presupposed.

\subsection{Interacting constraints in NP type and word order}

Although the focus of the present article clearly lies on the contribution of verbal semantics to the occurrence of DOM in colloquial spoken Italian, it is important to keep in mind that the agentive properties of the verb alone can never trigger DOM: as already mentioned in the introduction, they must always co-occur with (i) an object NP that is highly ranked in the Referentiality Scale and with (ii) a direct object situated in the left (or right) periphery of the sentence. Both additional requirements match typological tendencies: the first constraint (i), often associated with the semantic concept of definiteness, can be identified as a factor which cross-linguistically determines DOM (cf. e.g. Bossong 1991; Aissen 2003; Witzlack-Makarevich/Seržant 2018). The ranking of NP types can be exemplified by a version of the Referentiality Scale by von Heusinger (2008) in (25),

(25) Referentiality scale: PERSONAL PRONOUN > PROPER NAME > DEFINITE NP > INDEFINITE SPECIFIC NP > NON-SPECIFIC NP > NON-ARGUMENTAL

We have already pointed out in the Introduction that personal pronouns constitute a special case since, in Italian, they generally cannot occur in peripheral position without being $a$-marked. Interestingly for our purposes, common versions of the Referentiality Scale like the one in (25) do not include indefinite generic NPs. While many studies on indefinite NPs focus mainly on specificity (or its absence), the combination between DOM and genericity seems to be a rather understudied phenomenon. Evidence from the few studies on generics shows that in Spanish (Leonetti 2004) and Mandarin Chinese (Iemmolo/Arcodia 2014) the marker is required, while it is rejected in Romanian (Mardale 2008), Neo-Aramaic (Coghill 2014) and Tucano (Iemmolo 2010). In Italian, the marker is rejected with generic 
objects situated in a canonical postverbal position (as it is the case for other NP types in SVO structures):

(26) La matematica non affascina molto $\varnothing{ }^{*} a$ un filosofo. the mathematics NEG fascinate.PRS.3SG much DOM a philosopher 'Maths does not fascinate a philosopher that much.'

However, as already mentioned in the Introduction, its acceptability increases considerably if the generic object is pre-posed as the example in (27) illustrates:

(27) ${ }^{*} \varnothing /$ Ad un filosofo la matematica non affascina DOM a philosopher the mathematics NEG fascinate.PRS.3sG molto much

'To a philosopher maths does not fascinate that much.'

The second constraint (ii), non-canonical object position, has been intensively explored by Iemmolo (2010; in preparation) who provides cross-linguistic evidence for the hypothesis that differential object markers, such as Romance $a$, at least initially occurred in left (or right) detached position carrying a topic marking function. He proposes the following grammaticalization path of $a(d)+$ object $N P$ in Romance (Iemmolo in preparation, 266):

(28) LOCATIVE, ALLATIVE > (TOPIC) $>$ DATIVE > (DIFFERENTIAL) DIRECT OBJECT MARKER

A similar origin of DOM in Romance had been claimed by Pensado (1995, 202-203) who takes the topicalization of indirect and direct personal object pronouns as the starting point of the phenomenon. To put it briefly, the interaction of syntactic and NP-type constraints seems to reflect cross-linguistic tendencies in initial stages of DOM. It is one of the purposes of the present paper to shed light on the question how verb type constraints, more precisely role-semantic properties, enter the picture.

Based on the theoretical assumptions made in this Section, we designed an acceptability judgment task in order to systematically test the impact of rolesemantic and referential properties on DOM with CLLD objects in colloquial Standard Italian. 


\section{Judgment task}

We designed a questionnaire in order to assess the acceptability grade regarding the presence of DOM with peripheral objects exhibiting different proto-properties and different degrees of referentiality. Section 4.1 formulates the hypotheses based on the theoretical considerations made so far. Section 4.2 describes the study design in detail. Section 4.3 presents the results of the acceptability judgments of the marker according to the proto-properties and the referentiality level of the object. Finally, Section 4.4 discusses the results.

\subsection{Hypotheses}

In Berretta's corpus (1991), the overwhelming majority of $a$-marked objects was situated in the left periphery (Al gatto, io lo coccolo 'I cuddle the cat'), some sporadic cases of right dislocations were also attested (Vi aspetto più tardi, a tutt'e due 'I'll see you both in a while'), while not even one single case of objects in canonical position (SVO) has been reported. Moreover, $a$-marking only occurred with animate objects. In line with these results, Belletti (2018) points out that the $a$-marking of the object is a property of the left periphery and hence possible only with peripheral DOs. She also clearly states that the presence of the same $a$-marked objects in a canonical SVO structure would lead to the ungrammaticality of the sentence. To formulate our hypotheses, we start from the consideration that for the marker to occur, the object must be both animate and located in a peripheral position of the sentence.

In Section 3, it has also been pointed out that the types of verbs accompanying the object in Berretta's corpus assign non-prototypical properties to their DOs. That means, that, in the examples reported, the object exhibits at least one agentive property. This motivates our first hypothesis, according to which, in colloquial Italian, DOM is more likely to be accepted with agentive objects than with prototypical patients. Additionally, there is enough evidence for the claim that, cross-linguistically, the marker is more likely to occur with objects having a high level of referentiality, such as personal pronouns or proper names, than with, say, indefinite NPs (Aissen 2003; Dalrymple/Nikolaeva 2011). We built on this claim to put forward a second hypothesis, according to which DOM in colloquial Italian is more accepted with objects ranking high in the Referentiality Scale (cf. Aissen 2003) than with objects showing a low level of referentiality. The two hypotheses can be summarized as follows:

H1: In colloquial Italian, DOM is more accepted with objects showing agentive properties than with prototypical patients. 
H2: In colloquial Italian, DOM is more accepted with objects ranking high in the Referentiality Scale proposed by Aissen (2003) than with objects ranking low in such scale.

To assess if $\mathrm{H} 1$ is on the right track, we tested two classes of verbs where the object possesses agentive properties (OE-PSYCH-VERBS and INTERACTION VERBS) and one class of verbs where the object only exhibits proto-patient properties (HIGHLY TRANSITIVE VERBS). To test H2, we built items containing different NP types (pronouns, proper names, definite NPs and indefinite generics) and hence different degrees of individuation. The details of the study design are provided in the next section.

\subsection{Study design}

For our questionnaire, a group of 43 Italian-speaking adults ( $M A=26,0)$, mostly coming from Lombardy and Piedmont (Northern Italy) was recruited online. Speakers with possible interferences from any Southern-Italian dialects exhibiting DOM (e.g. Sicilian or Sardinian) have been excluded, as their judgments could have been biased by dialectal interferences.

Non-canonical structures, such as left dislocations, right dislocations and topicalizations, are generally used to mark information-structural functions (e.g. topicality) and are much more frequently found in the spoken, rather than the written, variety of the language. To guarantee a more natural effect, sentences were thus recorded by a native speaker of Italian. Participants were asked to listen to the sentences and judge their well-formedness, giving their intuition in a 1-to-5 estimation scale, where 1 represented "unacceptable" and 5 "totally acceptable". They were instructed to imagine an informal, spoken situation among friends or relatives. To facilitate the process of recruitment, all questionnaires were distributed online.

As stated in Section 4.1, within the items we manipulated both verb type and NP type, keeping the syntactic construction stable. That means that, except for the fillers, our critical items were only constructions containing a direct object situated in the left periphery of the sentence. We tested 3 verb classes (oE-PSYCH, INTERACTION, HIGHLY TRANSITIVE) and 4 NP types (pronouns, proper names, definite NPs, indefinite generic NPs). The questionnaire contained 20 critical items (cf. annexe) and 40 fillers which resulted in a dataset of 60 (items) x 43 (speakers), so that we obtained 2,580 judgments altogether. The presentation order of the entire material was randomized. The items are presented in detail in the following Section. 


\subsubsection{Items}

Within our critical items, we manipulated both verb type and NP type, testing 3 classes of verbs (OE-PSYCH-VERBS, INTERACTION VERBS, HIGHLY TRANSITIVE VERBS), 4 types of NPs (pronoun, proper name, definite NP, generic NP), and looking at their interaction. These interactions result in a total of 20 items (15 CLLD and 5 OVS), among which 4 combinations for OE-PSYCH-VERBS (2 lexicalizations + pronouns; 2 lexicalizations + proper names; 1 lexicalization + definite NPs; 4 lexicalizations + generics), 4 combinations for INTERACTION VERBS (2 lexicalizations + pronouns; 1 lexicalization + proper names; 2 lexicalizations + definite NPs; 1 lexicalization + generics) and 3 combinations for HIGHLY TRANSITIVE VERBS (1 lexicalization + pronoun; 2 lexicalizations + proper names; 2 lexicalizations + definite NPs). The selection of OE-PSYCH and INTERACTION VERBS was based on the inventory of lexical items contained in the corpus collected by Berretta (1991).

\section{Verb type:}

6 OBJECT-EXPERIENCER-PSYCH-VERBS (spaventare 'frighten'; affascinare 'fascinate'; innervosire 'make nervous'; convincere 'to convince'; entusiasmare 'to enthusiasm'; infastidire 'to annoy'). An example of the test item is provided in (29):

(29) Alla ragazza, la matematica non l' ha Dom.the girl the mathematics NEG CL.3SG have.PRS.3SG mai affascinata molto never fascinated much 'Maths never fascinated the girl that much.'

5 INTERACTION VERBS (aspettare 'wait'; ringraziare 'thank'; salutare 'greet'; accompagnare 'to accompany'; sposare 'to marry') such as in (30):

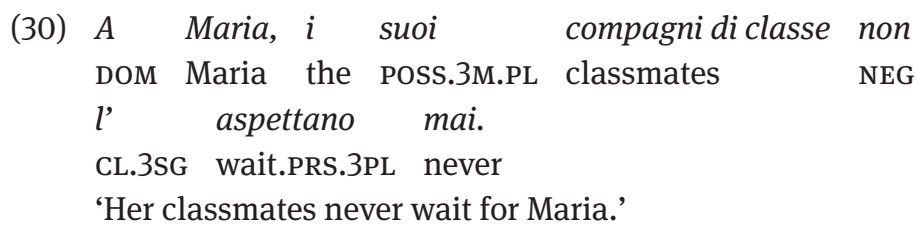

5 HIGHLY TRANSITIVE VERBS (ferire 'injure'; arrestare 'arrest'; uccidere 'kill'; prendere 'to catch'; fermare 'to stop'), as (31) shows: 
??A Giacomo, l' hanno arrestato ieri notte. DOM Giacomo CL.3SG have.PRS.3PL arrested yesterday night 'They arrested Giacomo last night.'

\section{NP type:}

3 a-marked personal pronouns (e.g. a lui 'him'; a lei 'her')

3 a-marked personal names (e.g. a Maria 'Maria'; a Gianni 'Gianni')

$3 a$-marked definite NPs (e.g. alla ragazza 'the girl')

3 a-marked generic NPs (e.g. ad un filosofo 'a philosopher')

To prevent participants from easily identifying the phenomenon under investigation, a considerable number of fillers (40 in total) was included. The group of filler sentences was divided in "good" and "bad" fillers. The good fillers included 20 fully grammatical SVO utterances, while the bad ones were composed by 20 illformed sentences that included agreement mismatches, wrong auxiliary-choice, incorrect use of preposition, etc.

Additionally, all oE-PSYCH-VERBS include an inanimate subject. The lack of animacy of the subject with this verb type guarantees its non-causative reading.

\subsubsection{Predictions}

We predicted the good fillers to be rated with 5 (totally acceptable) and the bad ones with 1 (totally unacceptable). As for the critical items, we expected participants to use the middle values $(2 ; 3 ; 4)$.

Predictions for the grammaticality judgments tasks based on $\mathrm{H} 1$ and $\mathrm{H} 2$ :

H1: If, in a transitive sentence, the prototypical AGENT-PATIENT-asymmetry cannot be established unequivocally because the DO bears any proto-agent property that is not expected in a typical transitive sentence, the AGENT-PATIENTasymmetry is blurred, and the marker becomes more acceptable.

P1: Based on the distribution of proto-agent vs. proto-patient properties of the verbs tested in our study (cf. Section 2.2), we predict the following scale of acceptability:

OE-PSYCH \& INTERACTION > HIGHLY TRANSITIVE

H2: In colloquial Italian DOM is better accepted with NP types ranking high in the Referentiality Scale identified by Aissen (2003).

P2: We expect the following ranking for the NP types we investigated: 
Regarding generics, the lack of robust previous literature makes it difficult to make predictions. For Spanish, various authors have pointed out that the occurrence of the marker with an indefinite determiner is rather marginal and often constrained by particular requirements (i.e., specificity, cf. Leonetti 2004). For some varieties of Spanish, like Cuban, acceptability judgments have shown that the lack of DOM with indefinite specific NPs is even more accepted than in the peninsular variety (cf. Caro Reina/García García/von Heusinger, this volume). However, the case of indefinites with a generic reading is different. According to Lambrecht "NPs whose referents identify either the whole class of all entities singled out by it or some representative set of members of this class, can be assumed to be identifiable" (1994, 82). Thus, although morphologically indefinites, their level of identifiability seems to be rather strong. In this case, they should be fairly accepted. The results of this study can provide indications on whether speakers rely more on the morphological form or the semantics of the NP in evaluating the occurrence of the marker.

\subsection{Results}

Figure 1 shows the ratings of 43 participants for the acceptability between DOM and different classes of verbs. OE-PSYCH-VERBS receive the highest rating (3.3), followed by INTERACTION VERBS (2.4) and HIGHLY TRANSITIVE VERBS (1.8). Interestingly, the ratings for INTERACTION VERBS is closer to the one of HIGHLY TRANSITIVE than OE-PSYCH-VERBS. The difference in the acceptability means of the three verb classes is, however, significant.

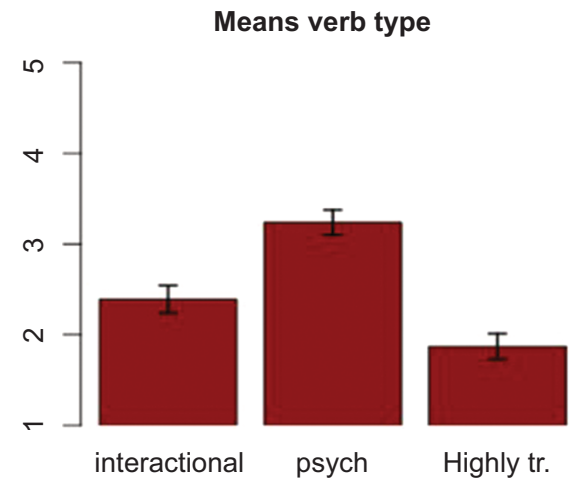

Figure 1: Means verb types. 
Figure 2 shows the participants' evaluations for different types of NP types. Pronouns display an acceptability rate of 2.6, followed by proper names (2.4) and definite NPs (2.2). Contrary to our expectations, indefinite generics seem to perform better than the other types, with a rating of 3.5. ${ }^{14}$ Besides generics, the remaining NP types seem to follow the Referentiality Scale so far predicted (Aissen 2003), where $a$-marked pronouns are better accepted than $a$-marked proper names, which, in turn, are better evaluated than less prominent NP types, like $a$-marked definite NPs. However, as confidence intervals show, while the difference between pronouns and proper names is significant ( $p$-value $=0.03$ ), the one between proper names and definite NPs is not ( $p$-value $=0.09)$.

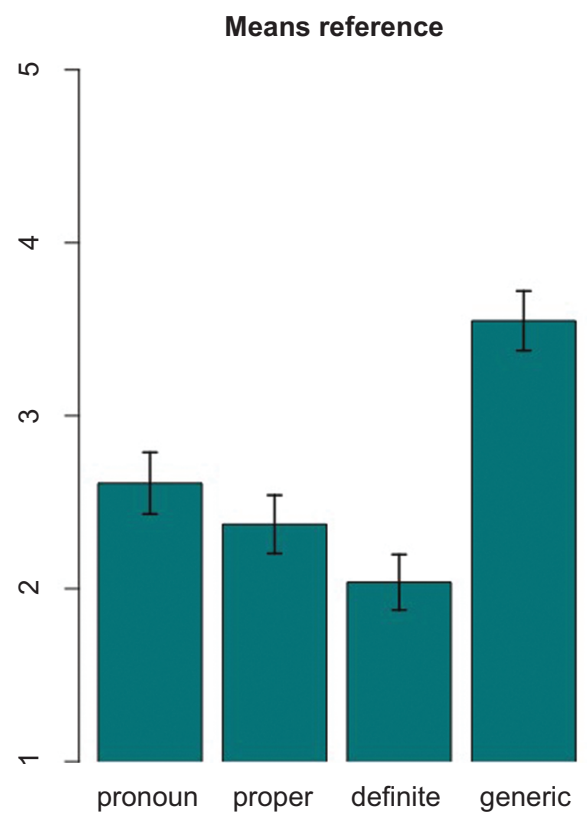

Figure 2: Means NP types.

The evaluations for the interaction between different NP types and oE-PSYCH, INTERACTION and HIGHLY TRANSITIVE VERBS are presented in Figures 3-5, respectively.

Both OE-PSYCH-VERBS and INTERACTION VERBS seem to perform better with indefinite generics (their interaction has received an evaluation of 3.6 and 3.2,

14 It is important to recall that indefinite generics have only been tested with OE-PSYCH-VERBS and one INTERACTION VERB, while the other NP types have been tested with all three verb types. 
respectively), a category that we had predicted as being situated low in the Referentiality Scale and, hence, less likely to be acceptable with the marker.

Apart from generics, our predictions are borne out only when it comes to the combination between INTERACTION VERBS and different NP types (Figure 4), where pronouns receive an average rating of 2.7 , followed by proper names (2.2) and definite NPs (1.9). Confidence intervals show that the difference between proper and definites in Figure 5 can still be considered significant ( $p$-value $=0.05$ ).

In the case of HIGHLY TRANSITIVE VERBS (Figure 5), there is no significant difference in the ratings of personal pronouns and proper names (2.09 and 2.04 respectively; $p$-value $=0.9$ ), while both differ significantly from definite NPs, that receive the lowest score (1.4).

OE-PSYCH-VERBS (Figure 4) even show a reverse referentiality effect, with definites (3.1) showing higher acceptability values than the other NP types (2.7 for pronouns, 2.8 for proper names). Confidence intervals display, however, that the difference in the rating of the three NP types is not significant (pronoun and proper: $p$-value $=0.7$; pronouns and definites: $p$-value $=0.6$; proper and definites: $\mathrm{p}$-value $=0.4)$.

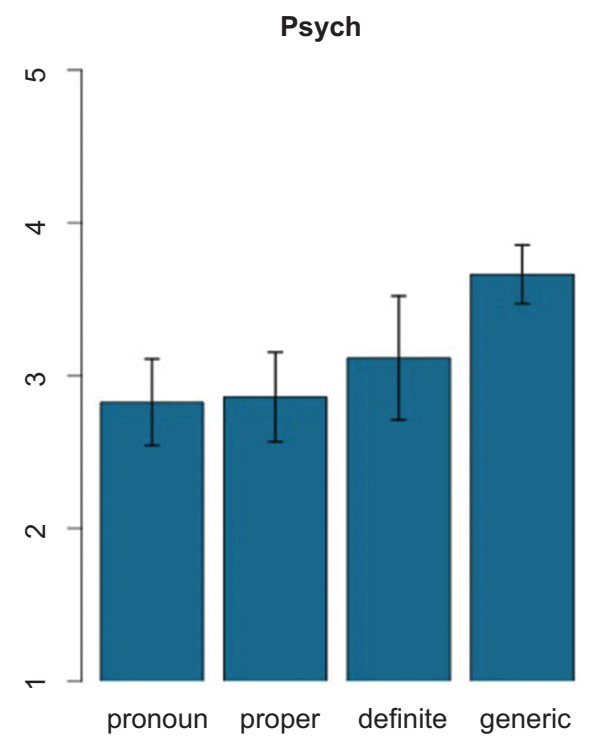

Figure 3: Means OE-PSYCH-VERBS (e.g. spaventare 'frighten') and NP type. 


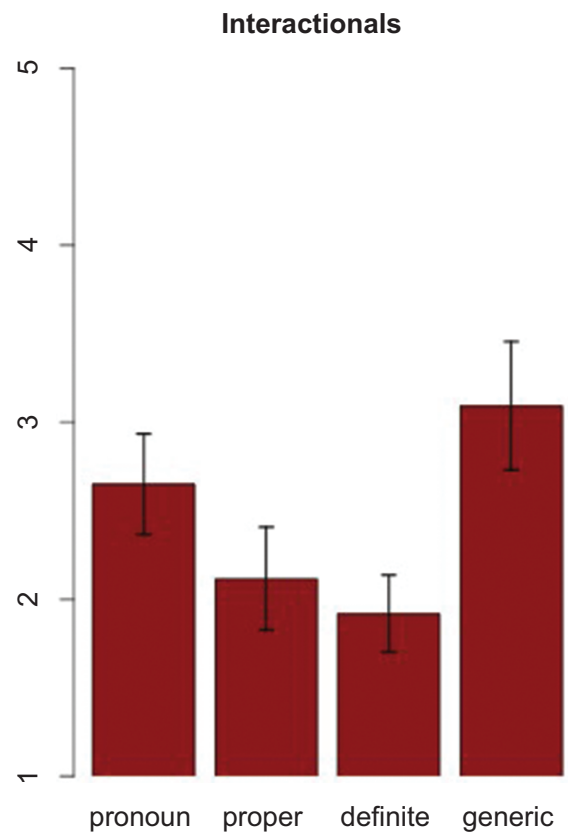

Figure 4: Means INTERACTION VERBS (e.g. aspettare 'wait') and NP type.

\section{Highly transitive}

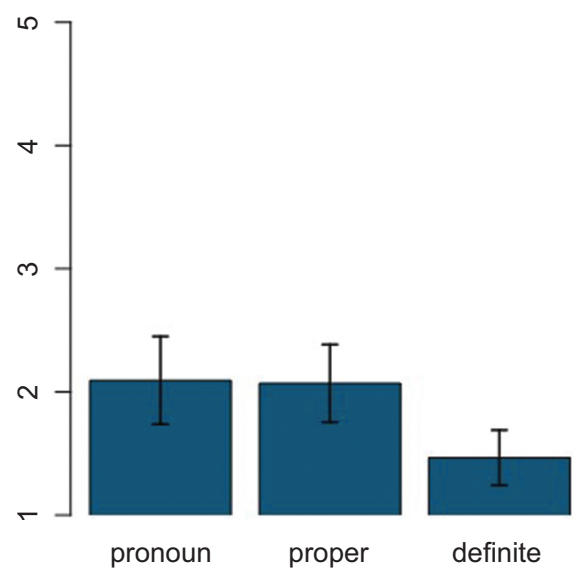

Figure 5: Means OE-PSYCH-VERBS (e.g. spaventare 'frighten') and NP type. 


\subsection{Discussion}

The results of the pilot study show that the acceptability of the tested items is generally rather low. It is possible to see, however, that there are differences in the judgments reported for each verb type. Recall that, according to H1, DOM is likely to occur when the traditional AGENT-PATIENT-asymmetry cannot be established unequivocally because the direct object bears some proto-agent properties.

OE-PSYCH-VERBS, where the direct object receives the thematic role of EXPERIENCER, are a clear example of a case where such AGENT-PATIENT-asymmetry is not as clear-cut, as the object possesses [+sentience], [+independent existence] and the subject, being the sTIMuLus, exhibits [+independent existence]. The validity of H1 is also supported by the comparison between the evaluation of OE-PSYCHVERBS (3.3) and the low ratings reported for HIGHLY TRANSITIVE VERBS (1.8), where the object bears only proto-patient properties. Thus, when the thematic role of the object is the prototypical patient, the marker is less (or even not at all) acceptable.

In the case of INTERACTION VERBS, both subject and object bear proto-agent properties while proto-patient properties are not assigned. In this case again, an AGENT-PATIENT-asymmetry cannot be established. Nevertheless, the results reported for INTERACTION VERBS (2.4) show an acceptability rate closer to HIGHLY TRANSITIVE VERBS (1.8) than to OE-PSYCH-VERBS (3.3) and, as such, considerably low. This result goes against our expectations. Our hypothesis was based on the assumption that, whenever a verb assigns at least one proto-agent property to its direct object, the marker should become more acceptable. Both INTERACTION and OE-PSYCH-VERBS fall into this category and should therefore perform in a similar way. However, this is not reflected in the ratings.

One possible explanation for the difference in the behaviour of the two verb classes could lie in the subtle distinctions at the level of their proto-properties. In Section 3, we mentioned the fact that verbs could either entail specific proto-agent properties for their arguments or presuppose them. While in the case of OE-PSYCHVERBS proto-agent properties are entailed for the object, INTERACTION VERBS only presuppose them. The two verb classes also exhibit a difference at the level of proto-agent properties exhibited by the subject. As Table 3 shows, the subject of an OE-PSYCH-VERB bears one proto-agent property in its non-causative reading, while the subject of an INTERACTION VERB bears up to four, including [+volition], a property typically found in subjects of HIGHLY TRANSITIVE VERBS. Whether this explanation could account for the difference in the evaluation of the two verb classes is yet to be assessed. A follow-up study, testing more lexicalizations for each verb type, would certainly reveal further insights. 
As for the NP type, our prediction according to which participants' evaluations would follow the Referentiality Scale identified by Aissen (2003) (cf. H2 $\mathrm{P} 2$, Section 3.2.2) is not borne out. Set aside dislocated pronouns, for which the marker is obligatory, proper names and definites don't show significant differences in their evaluations. Looking at their interaction with different verb types, pronouns perform better only with INTERACTION VERBS, while OE-PSYCH-VERBS even show an anti-referentiality effect, where definites override the other two NP types. To account for this result, one might assume an ongoing process of grammaticalization, for which the degree in referentiality of different NPs doesn't play a role anymore.

A noteworthy finding that emerges from our acceptability judgment task is the particular behaviour of indefinite generics. Differently from what we would have expected, their rating (3.5) is considerably higher than that of other NP types. A closer look at the semantic interpretation of genericity (Krifka 1987; Carlson 1995) suggests that generics, although introduced by an indefinite determiner, tend to behave like proper names, being interpreted as unique entities and having, therefore, a rigid reference. Leonetti (2004) notices that both specific and generic interpretations of indefinites belong to the family of strong interpretations, while non-specific interpretations are typically weak. This suggests that their classification within the Referentiality Scale might need to be rethought. Moreover, the overall low acceptability rates of our experimental items and the fact that indefinite generic NP-objects have better scores might be amenable to the same phenomenon: topicality. Low acceptability may be partially explained by the fact that object-preposing is a syntactically-marked construction, usually associated to backgrounded, topical information. Syntactically-marked constructions usually require additional contextual support, which is lacking in our items. This might have led to infelicity in context and low acceptability rates. Similarly, higher acceptability of indefinite-generic NPs may derive from the fact that for an indefinite NP to be interpreted as generic, it has to belong to the topical part of the utterance. Thus, while on the one hand, topicality lowers the acceptability of certain items, on the other hand, it increases the scores of generics of our indefinite NPs.

Such opposite effect might be due to the fact that, in out-of-the-blue contexts, generics are more felicitous than personal pronouns, personal names or definite NPs. Sentences containing a personal pronoun and deprived of context are somewhat artificial for speakers. On the contrary, generic statements, such as "philosophers are not attracted by mathematics" can possibly sound more natural and be, therefore, more acceptable. 
Whether this explanation is on the right track or not, the literature on the behaviour of generic objects and their interaction with DOM seems to be rather scarce and our results suggest that the phenomenon deserves further investigation.

The main aim of the current study was to give indications on whether different types of verbs might have an influence in the degree of acceptability of the marker with their respective DOs. Our results suggest that the type of verb might be one of the factors responsible for occurrence of DOM in Italian, given that the marker is better accepted with objects of OE-PSYCH-VERBS, exhibiting the thematic role of EXPERIENCER than with HIGHLY TRANSITIVE VERBS, where the object is the prototypical patient. The design of the task at this stage, however, presents several limitations and a more controlled experiment is still necessary. For instance, set aside the fillers, the test presented participants only with $a$-marked DOs. A condition where sentences with the same verbs are presented without the marker is still needed and will be the object of a more complete follow-up experiment.

Moreover, syntactic position has not been tested. Although the literature agrees on the claim that only peripheral objects are likely to be marked, it is necessary to assess such claim empirically and verify to what extent the acceptability rate of $a$-marked objects in SVO position differs from their peripheral correlates. Finally, the behaviour of generics still needs to be better assessed by testing more interactions with different verb types and possibly in different syntactic positions.

\section{Conclusions}

With the present paper, we have adopted an explanation in terms of role-semantic parameters for justifying the occurrence of Differential Object Marking in spoken colloquial Italian, a phenomenon that had been reported only from a descriptive perspective so far. We have investigated the well-formedness of sentences containing DOM in Italian by means of an acceptability judgment test, advancing the hypothesis that non-prototypical, agentive objects are more likely to be $a$-marked than typical, "patient-like” ones. Previous research on DOM has often explained such deviation from the prototypicality of the object in terms of animacy. With our study, we add a piece to this puzzle showing that, in colloquial Italian, the non-prototypicality of the DO also concerns its thematic role.

Moreover, the present article is a further contribution to the view that morphosyntactic phenomena like DOM are not sensitive to animacy exclusively but rather to agentivity, represented e.g. through the proto-agent property of sentience (cf. e.g. García García/Primus/Himmelmann 2018). This becomes evident 
when we have a look at Italian verbs like spaventare 'frighten' and uccidere 'kill': while both verbs select for an [+animate] direct object, only the former but not the latter allows for the $a$-marker in Italian. This constraint can be only explained in an agentivity-based but not in an animacy-based account. Whereas spaventare 'frighten' entails sentience for the object argument, uccidere 'kill' only assigns proto-patient properties to its object. Furthermore, the case of DOM in Italian is worth being investigated within a theory of grammaticalization: The fact that DOM underlies multiple constraints, namely syntactic construction, NP type as well as verb type, suggests that the phenomenon in Italian could be at an early stage of development and deserves to be further investigated in time to observe a possible expansion. Likewise, the robustness of the present account can be proved by a systematic analysis of (rare) instances of DOM in French put forward by Fagard/Mardale (2014), another Romance language where DOM is usually said to be absent. Their examples suggest that in French, like in Italian, different constraints must be fulfilled in order to allow DOM to appear. These comprise "inherent factors" of the object NP as well as so-called "global factors" which include not only topicality but also the verb type. A comparative account of French and Italian could reveal if the same role semantic properties lead to a preference for DOM in both languages.

\section{Annexe}

\section{OE-PSYCH-VERBS}

Visibilmente, a lei, certi argomenti non l'hanno convinta.

'Visibly, certain arguments didn't convince her.'

A lui, questa favola l'ha sempre spaventato.

'This fairy tale has always scared him.'

Alla ragazza, la matematica non l'ha mai affascinata molto.

'Maths never fascinated the girl that much.'

Ad Elena, i film di Tarantino non l'hanno mai entusiasmata.

'Elena was never thrilled by Tarantino's films.'

A Pietro, l'atteggiamento di Maria l'ha sempre innervosito.

'Mary's attitude has always made nervous Peter.' 


\section{Interaction verbs}

A Maria, i suoi compagni di classe non l'aspettano mai.

'Her classmates never wait for Maria.'

A me di sicuro Laura non mi saluta.

'Laura for sure doesn't greet me.'

Al professore, devi ringraziarlo sempre dopo la discussione della tesi.

'You should always thank the professor after the discussion of the thesis.'

A causa del suo atteggiamento, a lei, non la sposa nessuno.

'Because of her attitude, nobody marries her.'

Di solito, alla sposa, il padre l'accompagna all'altare.

'Usually, the father walks the bride down the aisle.'

\section{HIGHLY TRANSITIVE VERBS}

A Giacomo, l'hanno arrestato ieri notte.

'They arrested Giacomo last night.'

A lei, l'ha ferita Paolo.

'Paolo injured her.'

A Luca, l'hanno preso alla guida ubriaco.

'They caught Luca driving drunk.'

Alla vittima, l'ha sicuramente uccisa il marito.

'The victim was definitely killed by her husband.'

A tuo fratello, l'ha fermato ieri la polizia.

'The police stopped your brother yesterday.' 


\section{GENERIC NPS}

Ad una madre, certe cose infastidiscono.

'Some things annoy a mother.'

Ad un bambino questa favola generalmente spaventa.

'This fairy tale generally frightens a child.'

Ad un filosofo la matematica non affascina molto.

'Maths does not fascinate a philosopher that much.'

Ad un perenne ritardatario, alla fine, non lo aspetta più nessuno.

'A perpetual latecomer, in the end, is no longer expected.'

Di solito, ad un ragazzo, l'atteggiamento di Maria innervosisce.

'Usually, Mary's attitude makes a boy nervous.'

\section{Bibliography}

Ackerman, Farrell/Moore, John, Proto-properties and grammatical encoding. A correspondence theory of argument selection, Lingvisticæ Investigationes 29:2 (2006), 318-321.

Aissen, Judith, Differential Object Marking. Iconicity vs. economy, Natural Language and Linguistic Theory 21 (2003), 435-483.

Belletti, Adriana/Rizzi, Luigi, Psych-verbs and $\theta$-theory, Natural Language and Linguistic Theory 6 (1988), 291-352.

Belletti, Adriana, On a-marking of object topics in the Italian left periphery, in: Petrosino, Roberto/Cerrone, Pietro/van der Hulst, Harry (edd.), Beyond the veil of Maya. From sounds to structures, vol. 135, Berlin/Boston, de Gruyter, 2018, 445-466.

Benincà, Paola, Il lato sinistro della frase italiana, Balkan-Archiv 11 (1986), 213-243.

Berretta, Monica, Sulla presenza dell'accusativo preposizionale in italiano settentrionale. Note tipologiche, Vox Romanica 48 (1989), 13-37.

Berretta, Monica, Note sulla sintassi dell'accusativo preposizionale in italiano, Linguistica 31 (1991), 211-232.

Blume, Kerstin, A contrastive analysis of interaction verbs with dative complements, Linguistics 36:2 (1998), 253-280.

Blume, Kerstin, Markierte Valenzen im Sprachvergleich. Lizenzierungs- und Linkingbedingungen, Tübingen, Niemeyer, 2000.

Bossong, Georg, Differential Object Marking in Romance and beyond, in: Wanner, Dieter/ Kibbee, Douglas A. (edd.), New analyses in Romance linguistics. Selected papers from the Linguistic Symposium on Romance Languages XVIII, Urbana-Champaign, April 7-9, 1988, Amsterdam/Philadelphia, John Benjamins, 1991, 143-170. 
Bossong, Georg, Le marquage différentiel de l'objet dans les langues d'Europe, in: Feuillet, Jack (ed.), Actance et valence dans les langues de l'Europe, vol. 20, Berlin/New York, de Gruyter, 1998, 193-258.

Carlson, Gregory N./Pelletier, Francis J. (edd.), The generic book, Chicago, University of Chicago Press, 1995.

Coghill, Eleanor, Differential Object Marking in Neo-Aramaic, Linguistics 52:2 (2014), 335-364.

Croft, William, Case marking and the semantics of mental verbs, in: Pustejovsky, James (ed.),

Semantics and the lexicon, Dordrecht/Boston, Kluwer Academic Publishers, 1993, 55-72.

Dalrymple, Mary/Nikolaeva, Irina, Objects and information structure, Cambridge, Cambridge University Press, 2011.

Dowty, David, Thematic proto-roles and argument selection, Language 67:3 (1991), 547-619.

Fagard, Benjamin/Mardale, Alexandru, Non, mais tu l'as vu à lui? Analyse(s) du marquage différentiel de l'objet en français, Verbum 36:1 (2014), 143-168.

García García, Marco, Differential Object Marking with inanimate objects, in: Kaiser, Georg A./Leonetti, Manuel (edd.), Proceedings of the workshop "Definiteness, Specificity and Animacy in Ibero-Romance Languages", Arbeitspapier 122, Konstanz, Fachbereich Sprachwissenschaft der Universität Konstanz, 2007, 63-84.

García García, Marco, Differentielle Objektmarkierung bei unbelebten Objekten im Spanischen, Berlin/Boston, de Gruyter, 2014.

García García, Marco, Nominal and verbal parameters in the diachrony of Differential Object Marking in Spanish, in: Seržant, Ilja A./Witzlack-Makarevich, Alena (edd.), Diachrony of Differential Argument Marking, Berlin, Language Science Press, 2018, 209-242.

García García, Marco/Primus, Beatrice/Himmelmann, Nikolaus P., Shifting from animacy to agentivity, Theoretical Linguistics 44:1-2 (2018), 25-39.

lemmolo, Giorgio, Topicality and Differential Object Marking. Evidence from Romance and beyond, Studies in Language 34:2 (2010), 239-272.

lemmolo, Giorgio/Arcodia, Giorgio F., Differential Object Marking and identifiability of the referent. A study of Mandarin Chinese, Linguistics 52:2 (2014), 315-334.

lemmolo, Giorgio, Differential Object Marking, Oxford, Oxford University Press (in preparation).

Kabatek, Johannes, Wohin strebt die differentielle Objektmarkierung im Spanischen?, Romanistisches Jahrbuch 67:1 (2016), 211-239.

Kailuweit, Rolf, Linking. Syntax und Semantik französischer und italienischer Gefühlsverben, Tübingen, Niemeyer, 2005.

Kailuweit, Rolf, Romance object-experiencer verbs. From aktionstart to activity hierarchy, in: Barrajón López, Elisa/Cifuentes Honrubia, José Luis/Rodríguez Rosique, Susana (edd.), Verb classes and aspect, Amsterdam/Philadelphia, John Benjamins, 2015, 312-333.

Krifka, Manfred, An outline of generics, in: Forschungsberichte des Seminars für natürlichsprachliche Systeme, Tübingen, Universität Tübingen, 1987.

Kutscher, Silvia, Kausalität und Argumentrealisierung. Zur Konstruktionsvarianz bei Psychverben am Beispiel europäischer Sprachen, Tübingen, Niemeyer, 2009.

Lambrecht, Knud, Information structure and sentence form. Topic, focus, and the mental representations of discourse referents, Cambridge, Cambridge University Press, 1994.

Leonetti, Manuel, Specificity and Differential Object Marking in Spanish, Catalan Journal of Linguistics 3:1 (2004), 75-114.

Mardale, Alexandru, Microvariation within Differential Object Marking, Revue Roumaine de Linguistique 53:4 (2008), 449-467. 
Mürmann, Sophie, Differential Object Marking and role semantics in Romance, University of Cologne, Ph. D. thesis, 2021.

Pensado, Carmen, La creación del complemento directo preposicional y la flexión de los pronombres personales en las lenguas románicas, in: Pensado, Carmen (ed.), El complemento directo preposicional, Madrid, Visor, 1995, 179-233.

Primus, Beatrice, Cases and thematic roles. Ergative, accusative and active, Tübingen, Niemeyer, 1999 (= 1999a).

Primus, Beatrice, Rektionsprinzipien, in: Wegener, Heide (ed.), Deutsch kontrastiv. Typologischvergleichende Untersuchungen zur deutschen Grammatik, Tübingen, Stauffenburg, 1999, 135-170 (= 1999b).

Primus, Beatrice, Hierarchy mismatches and the dimensions of role semantics, in: Bornkessel, Ina, et al. (edd.), Semantic role universals and argument linking. Theoretical, typological, and psycholinguistic perspectives, Berlin/Boston, de Gruyter, 2006, 53-88.

Primus, Beatrice, Animacy, generalized semantic roles and Differential Object Marking, in: Lamers, Monique/de Swart, Peter (edd.), Case, word order, and prominence. Interacting cues in language production and comprehension, Dordrecht, Springer, 2012, 65-90.

Verhoeven, Elisabeth, Thematic prominence and animacy asymmetries. Evidence from a crosslinguistic production study, Lingua 143 (2014), 129-161.

von Heusinger, Klaus, Verbal semantics and the diachronic development of DOM in Spanish, Probus 20:1 (2008), 1-31.

von Heusinger, Klaus/Kaiser, Georg A., Affectedness and Differential Object Marking in Spanish, Morphology 21:3 (2011), 593-617.

Weissenrieder, Maureen, $A$ functional approach to the accusative "a”, Hispania 74:1 (1991), 146-156.

Witzlack-Makarevich, Alena/Seržant, Ilja A., Differential Argument Marking. Patterns of variation, in: Seržant, Ilja A./Witzlack-Makarevich, Alena (edd.), Diachrony of Differential Argument Marking, Berlin, Language Science Press, 2018, 1-40. 